DE DE GRUYTER

OPEN

圈

DOI: 10.1515/awutp-2016-0001
Analele Universității de Vest din Timișoara

Vol. LIX, 2016

Fizică

\title{
ERRATUM
}

Erratum to: Mihai Lungu, Raluca Giugiulan, Antoanetta Lungu, Madalin Bunoiu, Adrian Neculae,

\section{THE AHARONOV-BOHM EFFECT AND TRANSPORT PROPERTIES IN GRAPHENE NANOSTRUCTURES}

Annals of West University of Timisoara - Physics, Volume 57, Issue 1 (December 2013), Pages 86-95 (DOI:10.1515/awutp-2015-0110).

There was an error in the title of the paper. The correct title should read:

\section{FLUE GAS FILTRATION BY ENTRAPMENT OF NANOPARTICLES IN} A MICROFLUIDIC DEVICE USING DIELECTROPHORESIS

For the reader's convenience, the corrected reference is reproduced below:

Mihai Lungu, Raluca Giugiulan, Antoanetta Lungu, Madalin Bunoiu, Adrian Neculae, Flue gas filtration by entrapment of nanoparticles in a microfluidic device using dielectrophoresis, Annals of West University of Timisoara - Physics, Volume 57, Issue 1 (December 2013) 86-95 (DOI:10.1515/awutp-2015-0110). 